\title{
TECHNIQUE FOR COMPRESSING REGIONS OF INTEREST IN SIGN LANGUAGE VIDEOS
}

\author{
SIR-ALEXCI SUAREZ ${ }^{1} \&$ ALBERT MIYER SUAREZ ${ }^{2}$ \\ ${ }^{1}$ Engineering Faculty, University Francisco of Paula Santander Ocaña, Colombia \\ ${ }^{2}$ Engineering Faculty. University of Pamplona, Colombia
}

\begin{abstract}
The article presents a technique that allows reducing the size of videos composed of sign language frames, by extracting the region that performs the movement, eliminating the bidirectional frames. The size reduction is over $70 \%$ and can be stored in Matlab formats or traditional video format. The use of sign language is very important because it allows the communication of people with hearing problems, as well as the signaling of messages in all areas of industry, commerce and education. And it is the basis for incorporation into sources of employment and the reduction of limited risk areas in companies for personnel with this disability.
\end{abstract}

KEYWORDS: Image compression, digital image, sign language

Received: Oct 06, 2020; Accepted: Oct 26, 2020; Published: Nov 30, 2020; Paper Id.: IJMPERDOCT202074

\section{INTRODUCTION}

Technology-mediated sign language (LS) teaching includes tools where repositories are created with movement made to display each word or phrase (Castro Pinto et al., 2018; Mancheno \& Piedad, 2004; Rodríguez Mondoñedo et al., 2015). Sign language is not universal and each country maintains a different alphabet, but the way it is displayed has the same characteristics (Hernández, 2019). The form of presentation of the signs can be done with a live transmission of a speaker (INSOR, 2018), through videos obtained from the real movements of human beings (Consejo General de Educación, 2010) or using a humanoid like Visicast or by motion processing (Bragg et al., 2019; Elliott et al., 2000). All the tools have the same drawbacks that affect the transmission of the image; how is the weight of the files and the processing time (Bangham et al., 2000), which affects the speed and the message that must be uniform. Synchronous and asynchronous videos made by people present several problems such as the position of the instructor each time he incorporates a word, body movements and clothing accessories that can change in each section that will affect the recording sequences; in addition to the number of positions when using different cameras that make it difficult to reduce the weight of each stored image to display a sign (Al-khazraji et al., 2018).

Applications with humanoids are the ones that have had the greatest diffusion and are constantly being created in all sign languages, some are obtained by virtualizing human movements and others are carried out by means of the humanoid which contains segments that can be configured to simulate a movement, the latter are those that can increase in number of signs and made available to people with hearing disabilities on online platforms and desktop applications or App. The size of their files is quite large, despite the fact that the movements are repetitive in some areas such as the arms and hands. However, when forming a video, each image must be complete so as not to lose quality in the message of the signal, which ends up presenting a considerable amount of images (Bragg et al., 2018). 
A one-word sign can be made up of more than 80 frames with a weight that can be above $1 \mathrm{MG}$, using compression formats. The most used compression formats are: JPG, MPEG-4 and H2.64; The algorithm for compression is called Video Codec and the time it takes to display the video once it is decompressed is called latency; so it can be said that the more a file is compressed and the video codec is more complex there will be more latency (Rnds, 2015). When joining several images to create the signal, it is transformed into a video and the most common way of compression is by differentiating a pixel in a frame with that of another frame, creating before and after frames, but when using predictive frames, latency and size, and can only be decoded with the same encoding algorithm.

The objective of this article is to present a technique for reducing the size and latency occupied by the different frames that make up the movement in the LS, when using humanoid prototypes, through the use of arbitrary containers to store the areas of interest, which are small objects that differ from one frame to another.

\section{METHODOLOGY}

Each signal is contained in a video, the process followed for its subsequent compression is shown in Figure 1. First, all the frames that contain it are extracted, in itself one image per frame; then the first frame is stored unchanged in a container cell, this frame is called predictive; It continues with the second until the last frame, one by one the pixels that change their value are compared, and there is no need to take a distance because the same position of the pixel is compared between the previous and subsequent frame, this zone is extracted and stored in the next container cell, regardless of its dimension, these frames are called differentiators; at the end all the frame data is stored in a file. mat and are compared with the original signal to know the level of compression. If the original sign is represented by few frames, it is redesigned and the process is applied again to improve the transition quality of the frames. You can also apply a pre-processing by converting each color frame to shades of gray, all this process is done with Matlab, due to the power in the use of matrices and vectors and 35 videos of signs are used to measure its compression, and a video that has 72 frames is presented explaining the process.

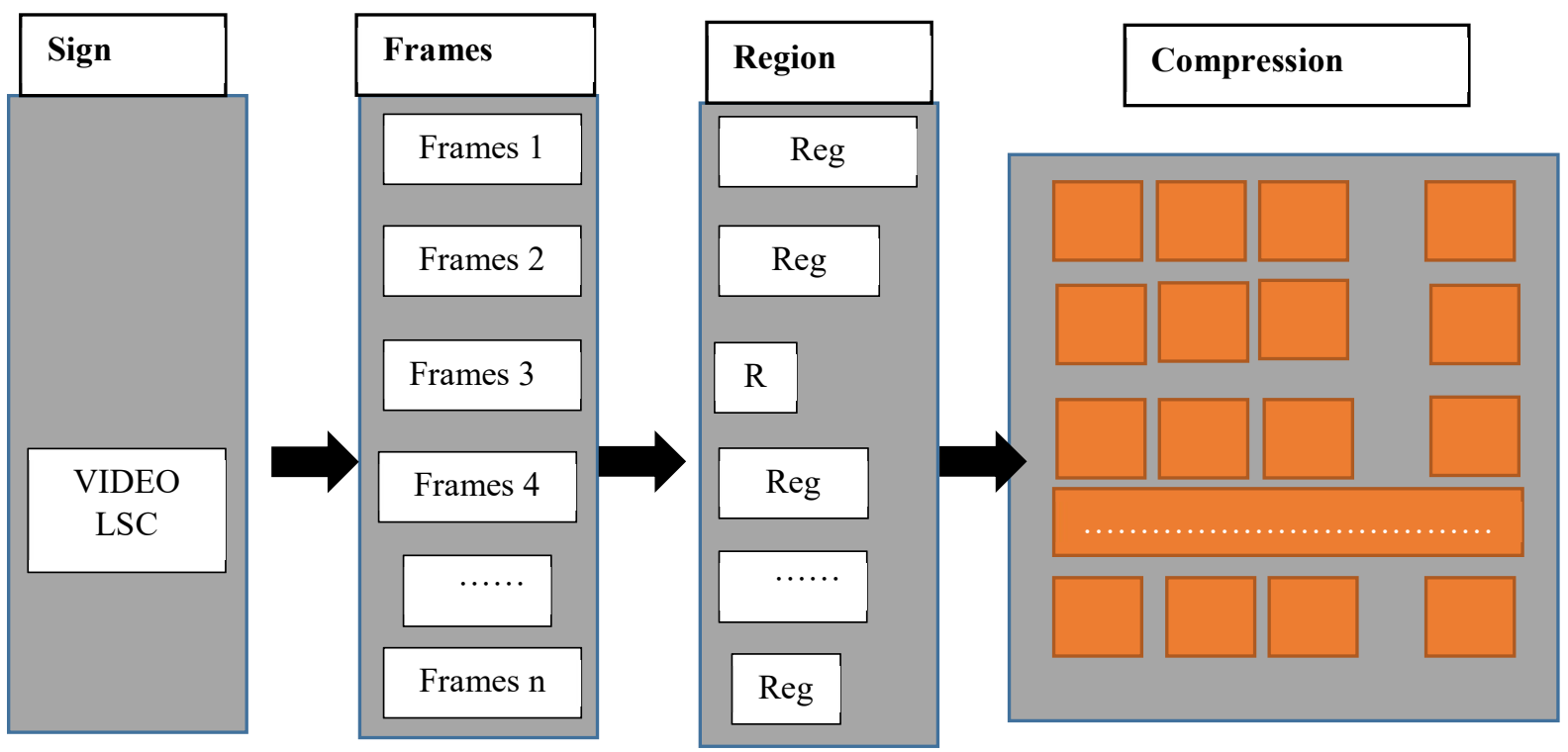

Figure 1: Compression process. 


\section{Compression Formats}

The compression formats (MPEG-4, H.264) use the reduction between frames, by means of the difference between the pixels that change from one frame to another, giving the impression that the images appear in a video with normal sequences. In figure 2, you can see the sign of the word "History", which has a weight of $795 \mathrm{~KB}$ and uses 76 frames with a dimension of $324 \times 436$, its normal weight without compression would be $2.04 \mathrm{MB}$, which is equivalent to LS video compression of more than $260 \%$. However, it still occupies a considerable space due to the number of frames that LS videos have.
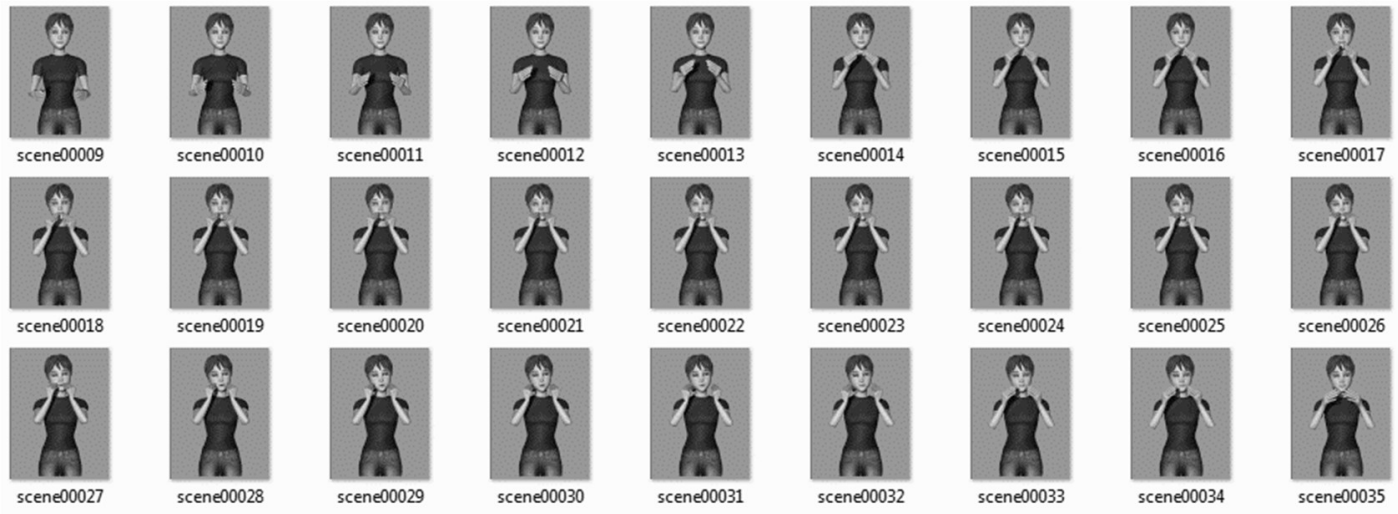

Figure 2: Fragments of frames for the History sign

In figure 3, the frames used for video compression are shown starting with the first frame as A, a bidirectional frame $\mathrm{B}$ referring to previous and subsequent frames and, a $\mathrm{C}$ frame which maintains the difference areas of the previous frame. In this way the "History" signal is compressed. The advantage of this system is that if a frame is damaged, it can rebuild it, but it loses latency and increases the amount of storage bits.

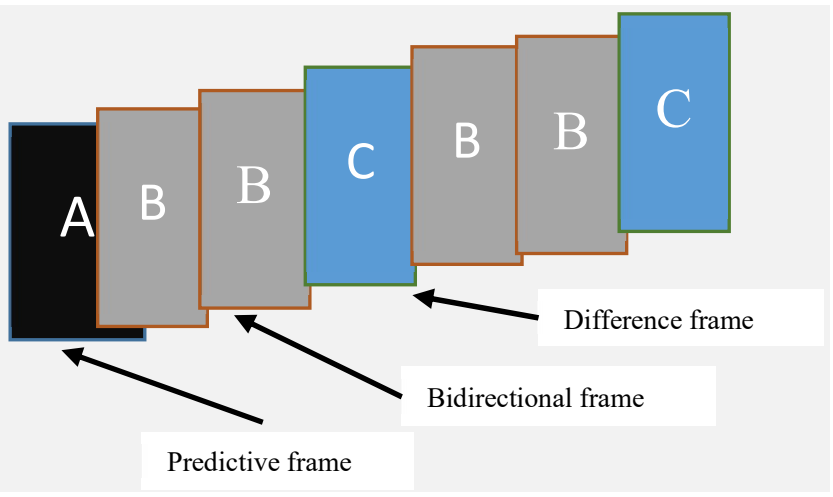

Figure 3: Compression frames.

Another way to do this is by resizing the image, however quality is lost and in most cases it cannot return to its original state when decoding it.

\section{RESULTS}

Arbitrary containers are cells of matrices that can store different types of data, with variable lengths, which allows to save frames of different sizes in the same matrix (Matlab, 2020). Each cell can be converted into a new matrix that stores the pixels of the image according to the region extracted from the previous frame. 
The first frame is called predictive and is stored in its entirety, subsequently the differentiating regions of each frame are extracted by comparing the value of each pixel according to its location, the bidirectional frames are eliminated (see figure 4), where the reconstruction of the Video frames are always made with the differentiating frames, evaluating the connectivity and adjacency of each pixel in this way reduces the weight of the video. In figure 4, you can see a fragment of frames and figure 5, once the regions that are different in each frame have been selected.
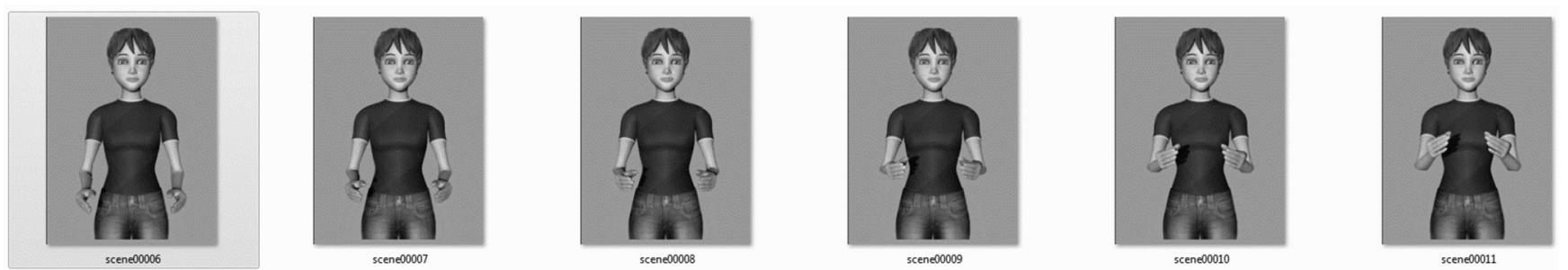

Figure 4: Fragments of frames for the History sign.
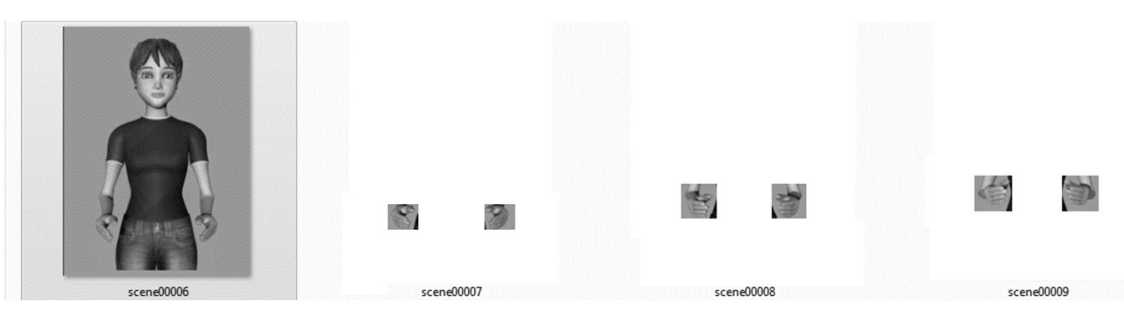

Figure 5: Regions of interest for the History sign.

The values of the region are calculated with four points that form a rectangular area: (x1, y1), (x2, y2), (x3, y3) and $(\mathrm{x} 4, \mathrm{y} 4)$; perpendicular lines are drawn based on the lowest value of the point $\mathrm{x} 1$ and $\mathrm{x} 3$, the highest value of the point $\mathrm{x} 2$ and $\mathrm{x} 4$; the smallest value of the point $\mathrm{y} 3$ and $\mathrm{y} 4$; and the largest value of the point (y1, y2). These zones can then be connected with adjacencies 4 when they are formed by horizontal and vertical neighbors or 8 when they are formed by the diagonal neighbors; they can be used when a frame is corrupted in such a way that it functions as bidirectional frames, even though the latency is higher. In table 1, 20 frames of the signal described above are shown, where the weights of each frame used are expressed through the compression format (AVI) and the container format. Each frame of the original sign maintains a similar weight which is compressed at the moment of conversion into a single video, while in the container only the first frame maintains its weight and then the size is already reduced, which can allow it to be used later a standard compression format.

Table 1: Building a cell array

\begin{tabular}{|l|l|l|}
\hline \multicolumn{1}{|c|}{ Frame } & \multicolumn{1}{c|}{ Original } & \multicolumn{1}{c|}{ Containers } \\
\hline 1 & $26.6 \mathrm{~KB}$ & $26.6 \mathrm{~KB}$ \\
\hline 2 & $26.1 \mathrm{~KB}$ & $5.21 \mathrm{~KB}$ \\
\hline 3 & $26 \mathrm{~KB}$ & $5 \mathrm{~KB}$ \\
\hline 4 & $25.9 \mathrm{~KB}$ & $5.3 \mathrm{~KB}$ \\
\hline 5 & $25.7 \mathrm{~KB}$ & $5.2 \mathrm{~KB}$ \\
\hline 6 & $25.6 \mathrm{~KB}$ & $5.4 \mathrm{~KB}$ \\
\hline 7 & $25.5 \mathrm{~KB}$ & $5.1 \mathrm{~KB}$ \\
\hline 8 & $25.3 \mathrm{~KB}$ & $4.8 \mathrm{~KB}$ \\
\hline 9 & $25.1 \mathrm{~KB}$ & $4.7 \mathrm{~KB}$ \\
\hline
\end{tabular}




\begin{tabular}{|l|l|l|}
\hline 10 & $25 \mathrm{~KB}$ & $5.2 \mathrm{~KB}$ \\
\hline 11 & $25.1 \mathrm{~KB}$ & $5.3 \mathrm{~KB}$ \\
\hline 12 & $25.4 \mathrm{~KB}$ & $5.6 \mathrm{~KB}$ \\
\hline 13 & $25.5 \mathrm{~KB}$ & $5.7 \mathrm{~KB}$ \\
\hline 14 & $24.9 \mathrm{~KB}$ & $5.3 \mathrm{~KB}$ \\
\hline 15 & $24.7 \mathrm{~KB}$ & $5.1 \mathrm{~KB}$ \\
\hline 16 & $24.7 \mathrm{~KB}$ & $4.8 \mathrm{~KB}$ \\
\hline 17 & $24.6 \mathrm{~KB}$ & $4.9 \mathrm{~KB}$ \\
\hline 18 & $24.3 \mathrm{~KB}$ & $4.7 \mathrm{~KB}$ \\
\hline 19 & $24 \mathrm{~KB}$ & $4.5 \mathrm{~KB}$ \\
\hline 20 & $23.9 \mathrm{~KB}$ & $4.2 \mathrm{~KB}$ \\
\hline
\end{tabular}

In Figure 6, you can see the reduction in size per frame, where it is equivalent to more than $80 \%$ of the original. Final file size reduces compression by $80 \%$, while latency decreases; the ease of decompression is similar and both are restricted by the fact that it can only be decoded with the appropriate video codec, in the case of containers with the algorithm developed for it, since it is stored in a .mat file. ; In resynchronization, the disadvantage is evident in relation to video formats, due to the fact that bidirectional frames have been eliminated, which maintain information from the previous and subsequent frames; with containers it is not used so at the moment of an error they must reuse the first frame, this could increase the latency;

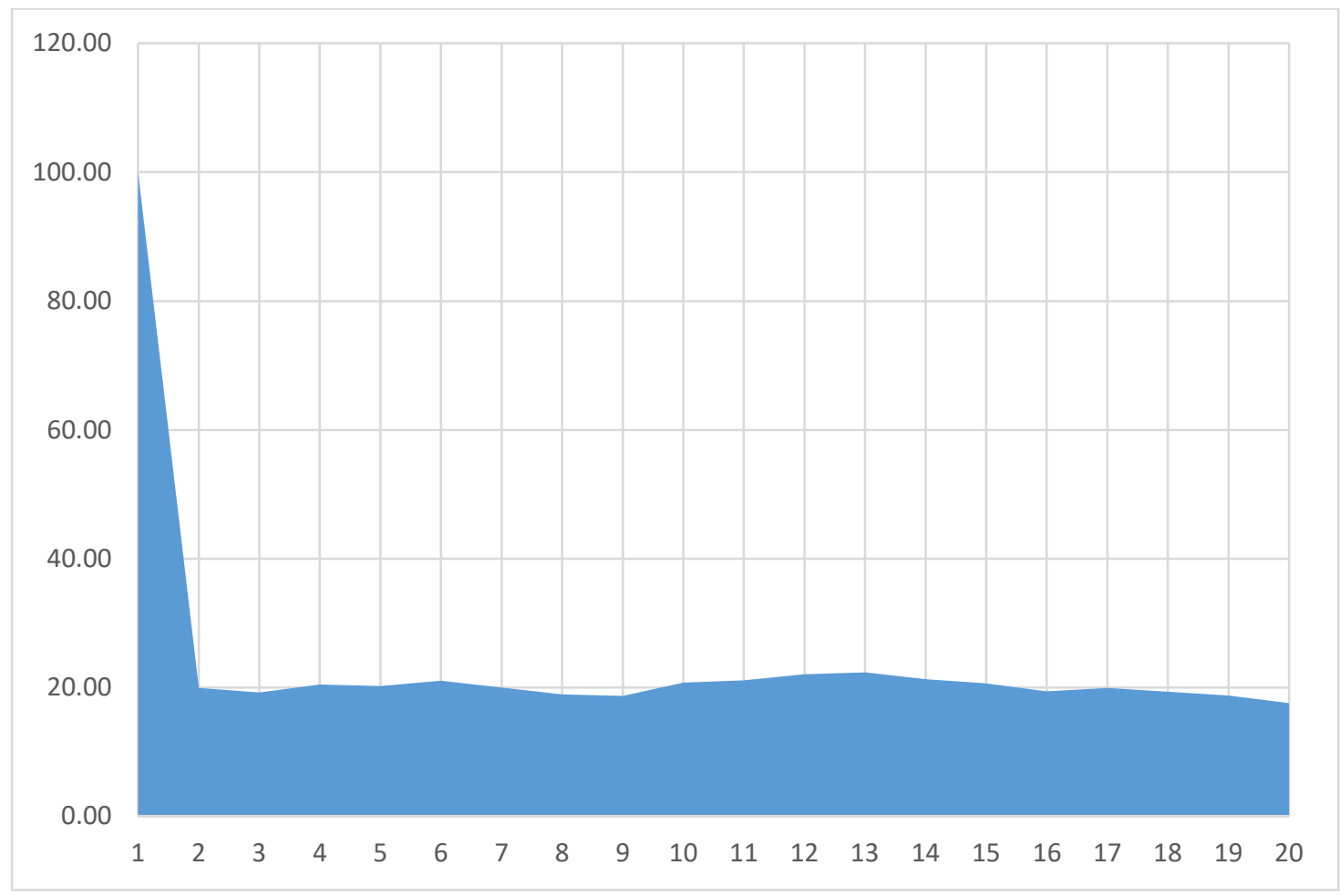

Figure 6: Size reduction per frame.

Of the 35 sign videos used, the reduction percentage remains between $75 \%-81 \%$,

\section{CONCLUSIONS}


People with disabilities have problems accessing sources of employment, as well as communicating with people in different areas, which brings communication consequences and loss of money to institutions and governments. The tools used for communication are based on videos by means of humanoids, but the size of these reduces the possibility of adding more words to the language. Research results show that eliminating bidirectional frames can reduce sign language videos, allowing more words to be added to the different tools that translate words into sign language; the reduction percentage reaches more than $70 \%$ presenting a technique that can be implemented efficiently.

\section{REFERENCES}

1. Al-khazraji, S., Berke, L., Kafle, S., Yeung, P., \& Huenerfauth, M. (2018). Modeling the Speed and Timing of American Sign Language to Generate Realistic Animations. 259-270. https://doi.org/10.1145/3234695.3236356

2. Bangham, A., Cox, S., Elliott, R., Glauert, J., Marshall, I., Rankov, S., \& Wells, M. (2000). Virtual signing: Capture, animation, storage and transmission-an overview of the ViSiCAST project. 6/1-6/7. https://doi.org/10.1049/ic:20000136

3. Bragg, D., Koller, O., Bellard, M., Berke, L., Boudreault, P., Braffort, A., Caselli, N., Huenerfauth, M., Kacorri, H., Verhoef, T., Vogler, C., \& Ringel Morris, M. (2019). Sign Language Recognition, Generation, and Translation: An Interdisciplinary Perspective. The 21st International ACM SIGACCESS Conference on Computers and Accessibility, 16-31. https://doi.org/10.1145/3308561.3353774

4. Bragg, D., Kushalnagar, R., \& Ladner, R. (2018). Designing an Animated Character System for American Sign Language. ASSETS. https://doi.org/10.1145/3234695.3236338

5. Castro Pinto, J. M. (Colaborador), Ortega Franco, D. F., López Leguizamón, H. A. (Colaborador), Caldas Espitia, Á. R. (Colaborador), Garay Porras, D. X., \& Rodriguez Pinto, C. P. (2018). Sistematización de Vocabulario Académico en Lengua de Señas Colombiana. http://repository.udistrital.edu.co/handle/11349/7959

6. Consejo General de Educación. (2010). Abecedario |Curso Taller Interactivo de Lengua de Señas Argentinas I| Subtitulado. https://www.youtube.com/watch? $v=$ UnPohorkKqY\&list $=$ PL1DF7AE9B0D9BD690

7. Elliott, R., Glauert, J. R. W., Kennaway, J. R., \& Marshall, I. (2000). The development of language processing support for the ViSiCAST project. Proceedings of the fourth international ACM conference on Assistive technologies, 101-108. https://doi.org/10.1145/354324.354349

8. Hernández, J. (2019). ¿Sabias que el lenguaje de signos es diferente en cada pais? La Gaceta de Salamanca. https://www.lagacetadesalamanca.es/salamanca/sabias-que-el-lenguaje-de-signos-es-diferente-en-cada-pais-BE1655452

9. INSOR. (2018). Clases en vivo de Lenguaje. INSOR Educativo. http://educativo.insor.gov.co/recursoseducativos/lenguaje/contenidos-lenguaje-secundaria/clases-en-vivo-de-lenguaje/

10. Mancheno, A., \& Piedad, G. (2004). Manual de lengua de señas. http://repositorio.ute.edu.ec/xmlui/handle/123456789/9715

11. Matlab. (2020). What Is a Cell Array? - MATLAB \& Simulink-MathWorks América Latina. https://la.mathworks.com/help/matlab/matlab_prog/what-is-a-cell-array.html

12. Rnds. (2015). Compresión de video. Negocios de seguridad, Tecnología video en red-Capitulo VII. http://www.rnds.com.ar/articulos/059/cap_07.pdf

13. Rodriguez Mondoñedo, M., Arnaiz, A., \& Maruenda, S. (2015). Repositorio Lengua de Señas Peruana http://repositorio.pucp.edu.pe/index/handle/123456789/46588. 